\title{
THE CONGLUTINATION PHENOMENON
}

\section{FURTHER EXPERIMENTS ON THE IMPORTANCE OF THE CHOICE OF COMPLE- MENT WHEN EXAMINING ANTISERA FOR THE PRESENCE OF COMPLEMENT- FIXING OR COMPLEMENT-ABSORBING ANTIBODIES}

\author{
By A. M. BLOMFIELD,* R. R. A. COOMBS $\dagger$ and N. H. HOLE \\ From the Department of Pathology, University of Cambridge, and the \\ Veterinary Laboratory, Ministry of Agriculture, Weybridge
}

(With 14 Figures in the Text)

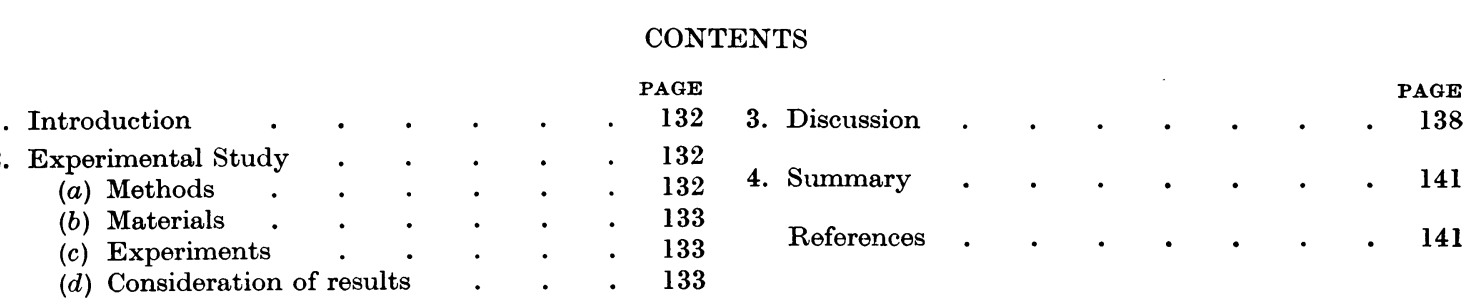

\section{INTRODUCTION}

In a previous paper (Coombs \& Hole, 1948) we showed how the demonstrable titre of complementfixing antibodies present in the sera of certain species of animals depended on which type of complement was used in the test. Using six different complements, which is possible if advantage is taken of the conglutinating complement-absorption test $\ddagger$ (Hole $\&$ Coombs, $1947 a, b, c)$ together with the usual haemolytic complement-fixation test, $\S$ we reported the antibody titres obtained when testing antimallein sera produced in horses, donkeys, pigs, dogs, cats, man, rabbits and guinea-pigs. In the sera of some species we were only able to demonstrate the presence of complement-fixing antibodies by the use of a particular complement; some complements were not visibly fixed, although we knew antibodies were present.

This paper is a continuation of the investigations, in which we record the results of similar experiments with anti-mallein sera produced in cows, sheep, goats, fowls, ferrets, rats and hamsters.

Dean (1917) showed clearly that in a given period of time more guinea-pig complement is fixed by an antigen-antiserum system at $4^{\circ} \mathrm{C}$. than at $17^{\circ} \mathrm{C}$ or $37^{\circ} \mathrm{C}$.; with the systems he used he obtained maximal fixation after $10 \mathrm{hr}$. at $4^{\circ} \mathrm{C}$. Consequently, in

* With a grant from the Agricultural Research Council.

$\dagger$ John Lucas Walker Student, Cambridge.

$\ddagger$ Hereinafter referred to as the C.C.A.T.

$\S$ Hereinafter referred to as the H.C.F.T.

these experiments, two methods of fixation have been used and compared; in one series of tests our usual fixation period of half an hour at room temperature was employed, and in a parallel series overnight fixation at $4^{\circ} \mathrm{C}$. $\|$ As our previous paper (Coombs \& Hole, 1948) dealt only with conditions of room temperature fixation, tests there reported on the various sera have all been repeated using both methods of fixation, and the results are included in this paper.

\section{EXPERIMENTAL STUDY}

\section{(a) Methods}

The anti-mallein sera produced in the different animal species were tested for their content of specific complement-fixing or absorbing antibodies by the C.C.A.T. and the H.C.F.T. The methods used in these experiments have been described in detail in previous papers (Coombs \& Hole, 1948, and Hole \& Coombs, 1947b). The results obtained with haemolytic guinea-pig complement and conglutinating pig, horse and cat complements have been compared. We have not carried out further tests with the conglutinating complements present in human and dog sera because samples of satisfactory titre are difficult to obtain, do not preserve well and their use in the earlier experiments did not suggest the likelihood of any advantage.

|| Hereinafter these two conditions of fixation are referred to as room temperature fixation and overnight fixation. 
Each serum was tested by the room temperature and overnight fixation methods. The respective complement titrations were carried out under similar conditions, i.e. by standing the complement dilutions either for half an hour at room temperature, or overnight at $4^{\circ} \mathrm{C}$., in contact with the antigen, before adding the haemolytic or conglutinating systems.

The mallein antigen dilution used in all tests was 1 in 700 , a dilution well within the optimal range when tested with horse, bovine, or ferret antisera and any of the complements, irrespective of the method of fixation. The importance of the mallein antigen dilution factor has been discussed in a previous paper (Hole \& Coombs, 1947b).

\section{(b) Materials}

Antisera. The anti-mallein sera were produced as described in our previous paper (Coombs \& Hole, 1948). All the sera were stored at $-20^{\circ} \mathrm{C}$., and inactivated at $56^{\circ} \mathrm{C}$. for half an hour before testing.

The horse, cat, bovine, sheep, goat, fowl, ferret, rat and hamster sera were obtained after a single course of immunization. The human $C$ antiserum was obtained after a second course. These sera were all tested within 2 months of their production. The rest of the sera were stored for about 10 months at $-20^{\circ} \mathrm{C}$. before the tests were performed; of these the human $\mathrm{K}$ serum was from a case of melioidosis, the pig and guinea-pig sera were first course antisera, while the dog serum and the rabbit serum were from a bleeding after a second course of inoculation.

Ferret 2 serum was a pool of two sera, rats 145 and 10 sera pools of three, hamster 256 and 257 sera pools of two and guinea-pig pool serum a pool of three sera.

Antigen. The preparation of the mallein antigen has already been described (Coombs \& Hole, 1948). It was used at the optimal dilution of 1 in 700 .

Complements. The conglutinating complements used were the fresh, unheated sera of the pig, horse and cat, and the haemolytic complement that of the guinea-pig; all the complements were preserved frozen at $-20^{\circ} \mathrm{C}$.

Other reagents. The conglutinating indicator system consisted of equal parts of a $0.3 \%$ sheep red cell suspension and bovine serum inactivated at $56^{\circ} \mathrm{C}$. for half an hour; the dilution of the bovine serum was 1 in 20 , which represented two to four 'apparent minimal conglutinating doses'. The haemolytic indicator system consisted of equal parts of a $1 \%$ sheep red cell suspension and a dilution of horse anti-sheep red cell haemolysin containing three minimal complete haemolytic doses.

\section{(c) Experiments}

The experiments and their results are summarized in Figs. 1-14, which record the titre of specific antibodies demonstrated by testing each serum for its ability to fix complement, using exactly 2 M.C.D. of each of the four types of complement. The results obtained with room temperature fixation and with overnight fixation are compared side by side.

All the preinoculation sera were tested and found to be negative except the normal sheep and goat sera. These fixed pig, horse and cat complements in the presence of the mallein antigen. However the titres of these normal antibodies in the sheep and goat sera did not exceed twenty.

In all tests controls were set up to record any anticomplementary action of the serum; anticomplementary action for any particular complement is illustrated in the figures by a black column.

\section{(d) Consideration of results}

The results of the experiments can be seen by inspecting Figs. 1-14. From a consideration of these figures it is possible to determine which is the best complement to use in the examination of a serum, belonging to any of the species tested, for the content of complement-fixing antibodies.

Tests on the immune sera of the horse, pig, dog, cat, rabbit, guinea-pig and man have been published in a previous paper (Coombs \& Hole, 1948), and any reference to previous results, in this subsection, refers to that paper.

Horse sera. The horse sera tested fixed all four types of complement well. The highest titre for the antisera was obtained with horse complement. The antisera used in this experiment were two new samples, and the results obtained compare favourably with those previously recorded.

Pig sera. The pig sera gave irregular results, horse complement being the only type to be consistently fixed. Pig $\mathrm{C} 2$ gave the same picture as that obtained when it was tested before; pig $\mathrm{C} 1$ serum however, in this experiment, showed fixation of pig and cat complements, whereas negative results were obtained with these complements in the original tests. We consider that the ageing of the serum may have played a part in this discrepancy. Fixation of guinea-pig complement is brought about by the use of overnight fixation.

Dog sera. Both the dog sera were taken from animals used for the previous tests, after submitting them to a second course of inoculation. On the whole, the pattern of results, as depicted in Fig. 3, agrees with that found before. Horse complement again gave the best results, but these are somewhat marred by the fact that the dog sera were very anticomplementary for horse complement. Overnight fixation with pig complement showed a reaction with $\operatorname{dog} \mathrm{L}$ not obtained with room-temperature fixation.

Cat sera. Two new immune cat sera were used in these experiments, and the results obtained confirm our earlier results with cat sera. Guinea-pig complement was fixed only after overnight fixation, and in the case of one serum there were slight indications 
of fixation of pig complement under similar conditions. Horse complement was again the most consistent and revealed the highest antibody titres; unlike the dog sera, the cat sera were not anticomplementary to horse complement.

Human sera. The human $\mathbf{K}$ serum from a patient with melioidosis was the same serum as was ex- second-course serum, differed from that of the first course by showing a fixation of guinea-pig complement, although only at a very low titre.

Human antisera demonstrate clearly the benefit of using horse complement in complement-absorption tests.

Rabbit sera. The rabbit sera were second course
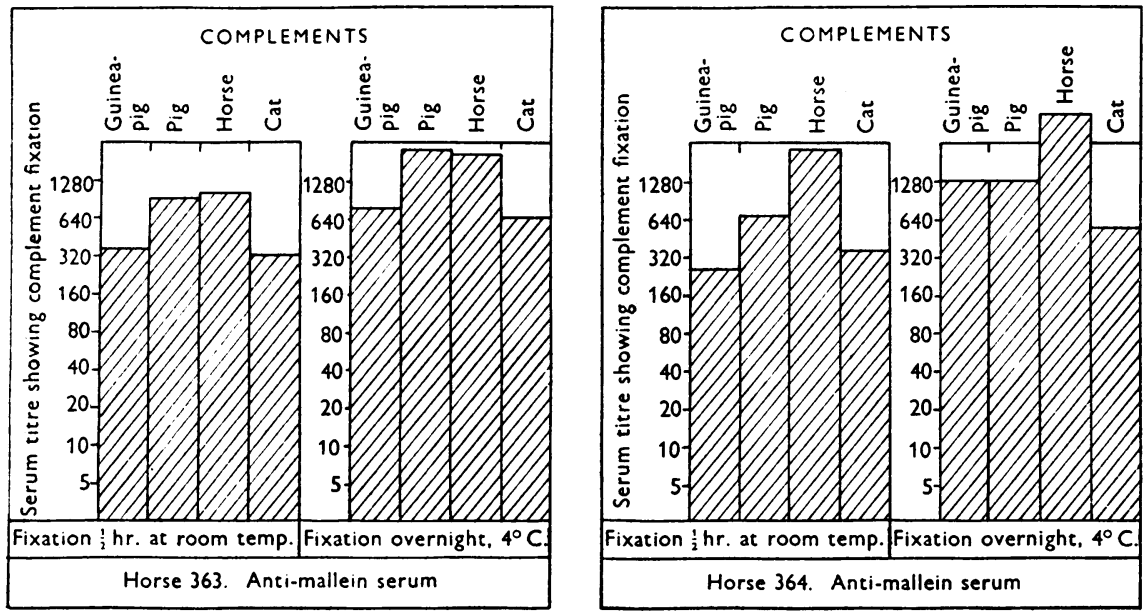

Fig. 1. The demonstrable titre of specific antibodies to mallein in two horse sera using four different complements Key relating to all figures: Complete fixation of complement. $\square$ Partial fixation of complement.

Anti-complementary action of serum. $\square$ No apparent fixation of complement. May indicate a prozone.
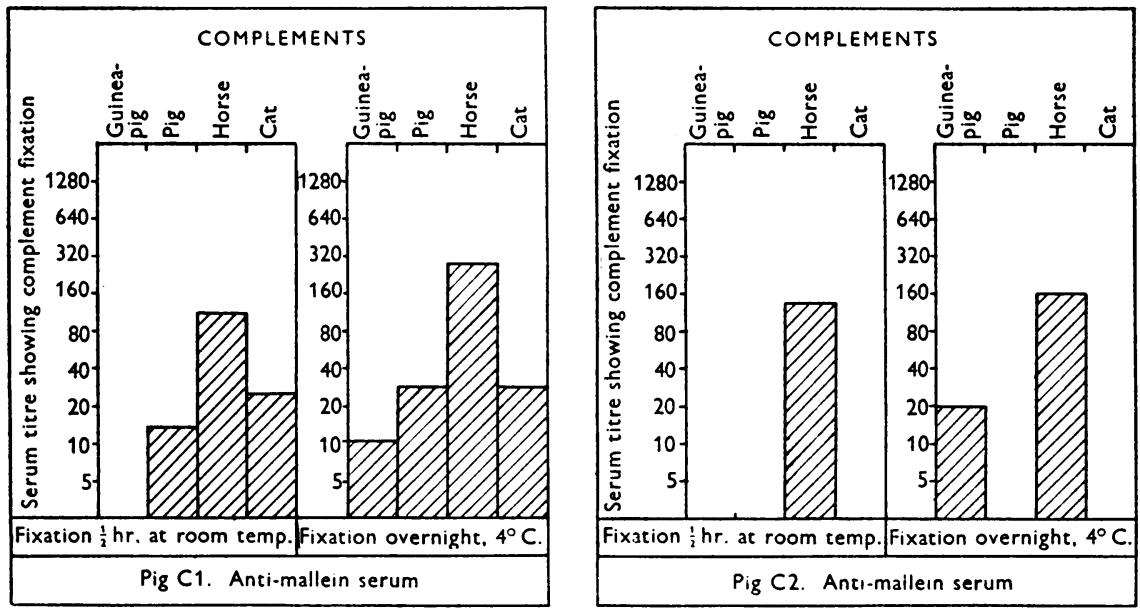

Fig. 2. The demonstrable titre of specific antibodies to mallein in two pig sera using four different complements.

amined before. This serum, when tested soon after it was obtained, showed definite fixation of cat complement, while after 2 months' storage at $-20^{\circ} \mathrm{C}$., as mentioned in our previous paper, irregular results were obtained and now, after 10 months' storage, fixation of cat complement was only obtained over a narrow zone. The human $\mathrm{C}$ serum, which was a bleedings from animals used in the previous experiment. They illustrate a type of serum which has the property of fixing well all the complements tested, and overnight fixation made no appreciable difference to the titres obtained except perhaps in the case of guinea-pig complement.

Guinea-pig sera. Tests with these guinea-pig sera 
REVISED KEY RELATING TO ALL FIGURES

(See legend to Fig. 1, page 134)

Complete fixation of complement

Anti-complementary action

\section{of serum}
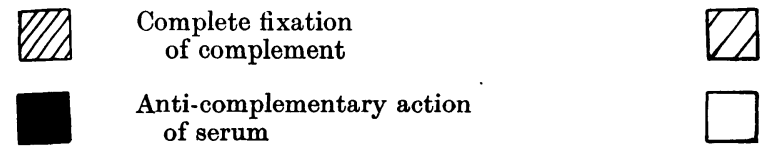

\author{
Partial fixation \\ of complement \\ No apparent fixation \\ of complement. \\ May indicate a prozone
}


confirm our previous findings. Overnight fixation markedly enhances the fixation of guinea-pig complement.

\section{Sera from animals not previously investigated}

Bovine, sheep and goat sera. The patterns of the results obtained with the antisera from cows, sheep and goats are very similar. Once again the comple- cal; however it can be shown that should the antibody titre in a bovine serum, inactivated in the normal manner $\left(56^{\circ} \mathrm{C}\right.$. per half an hour $)$, be very low, the excess of conglutinin present may mask the fixation of small amounts of conglutinating complement by enhancing the activity of any unabsorbed complement.

An interesting, although unaccountable, observa-
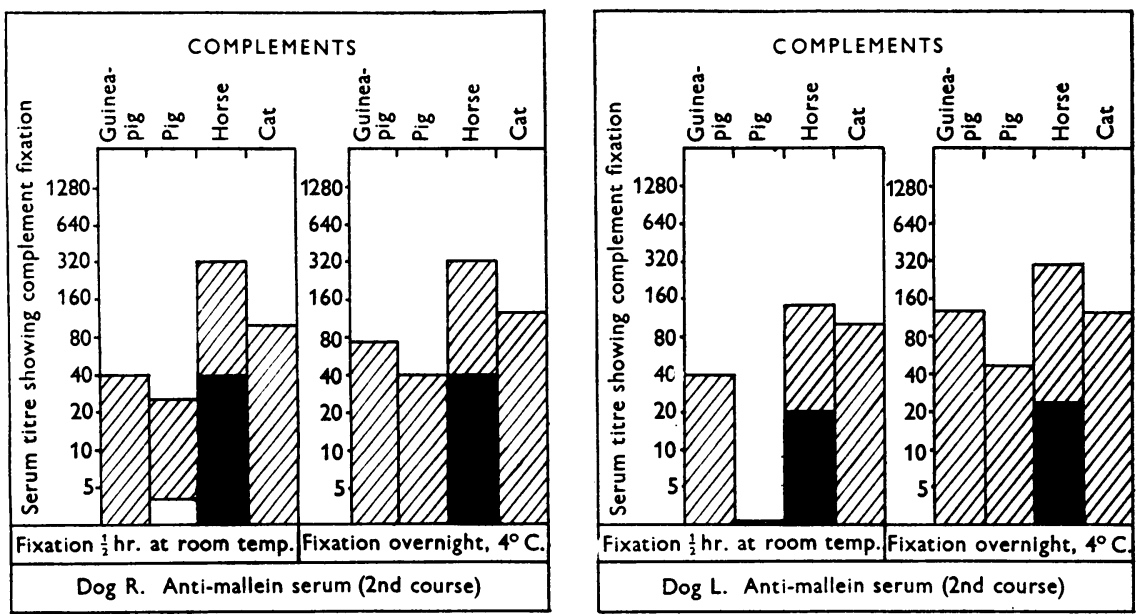

Fig. 3. The demonstrable titre of specific antibodies to mallein in two dog sera using four different complements.
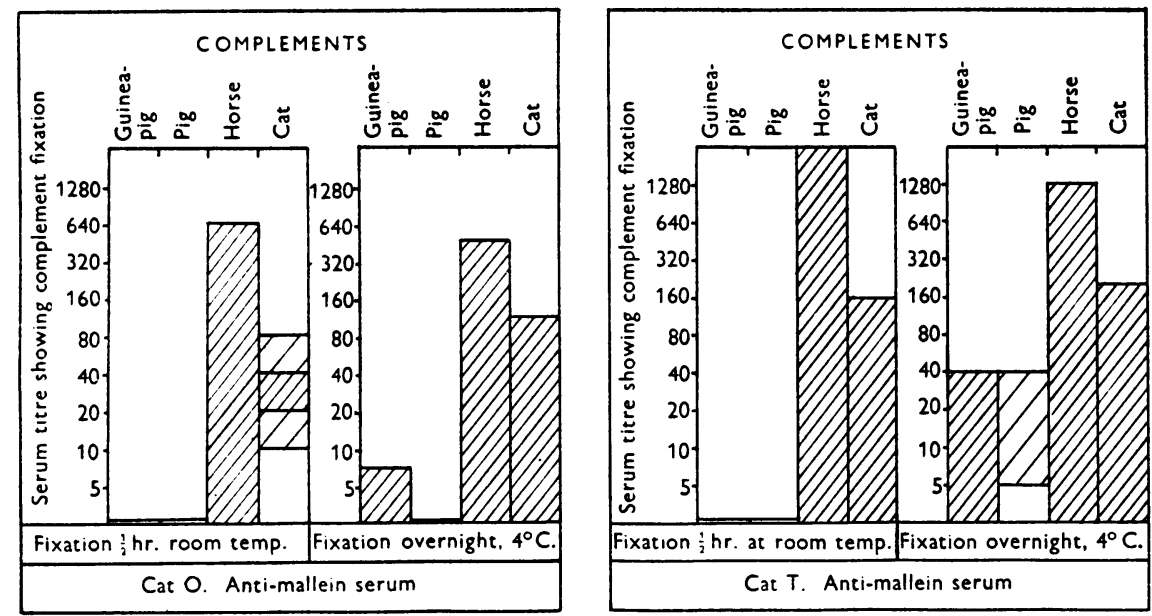

Fig. 4. The demonstrable titre of specific antibodies in mallein in two cat sera using four different complements.

ment of the horse appears to be the most sensitive in detecting the antigen-antibody combination. The sheep and goat sera were anticomplementary to pig and cat complements. The bovine antisera were reexamined after heating at $60^{\circ} \mathrm{C}$. for half an hour instead of the usual $56^{\circ} \mathrm{C}$., with the object of destroying most of the activity of the conglutinin present. The results obtained with the sera heated to these different temperatures were practically identi- tion on bovine antisera was made independently both at the Cambridge and Weybridge laboratories. When these antisera were tested very shortly after the blood had been drawn, guinea-pig complement was not fixed by the inactivated sera, but was fixed if the latter were used unheated; however, after storage for 3-4 weeks at $-20^{\circ} \mathrm{C}$., serum subsequently inactivated showed a definite fixation of guinea-pig complement. 
The fixation of guinea-pig complement, and to a lesser degree that of the pig, by bovine, sheep and goat antisera, is certainly improved by overnight fixation.

Fowl sera. We were unable to show fixation of any of the complements by the two fowl sera illustrated, and had similar negative results with four other fowl antisera not mentioned in this paper.
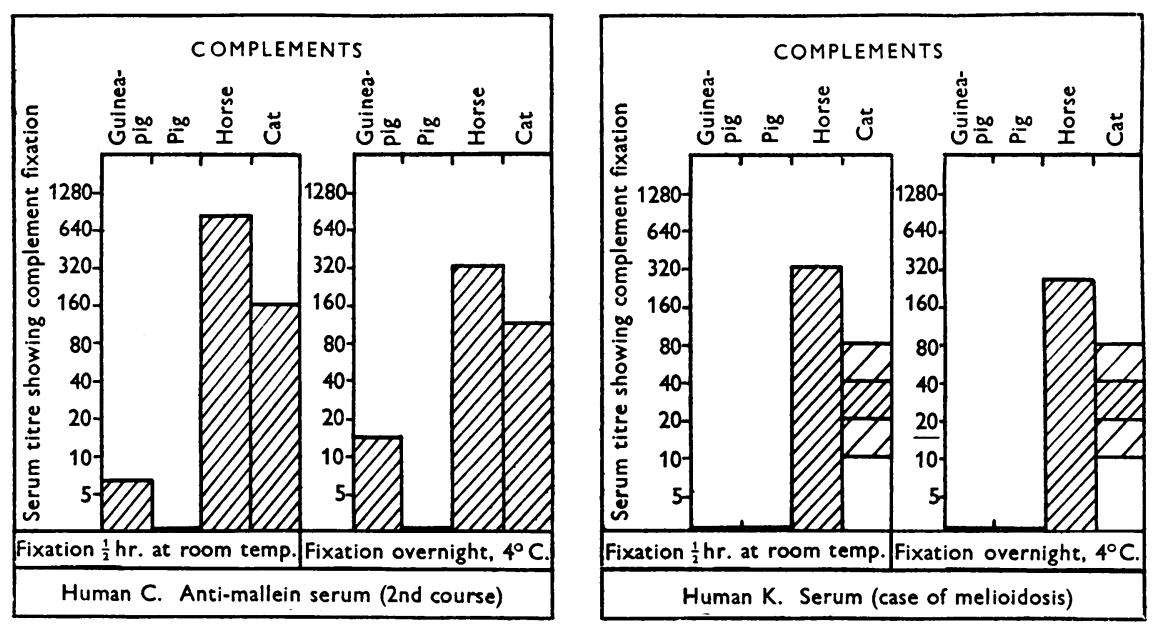

Fig. 5. The demonstrable titre of specific antibodies to mallein in two human sera using four different complements.
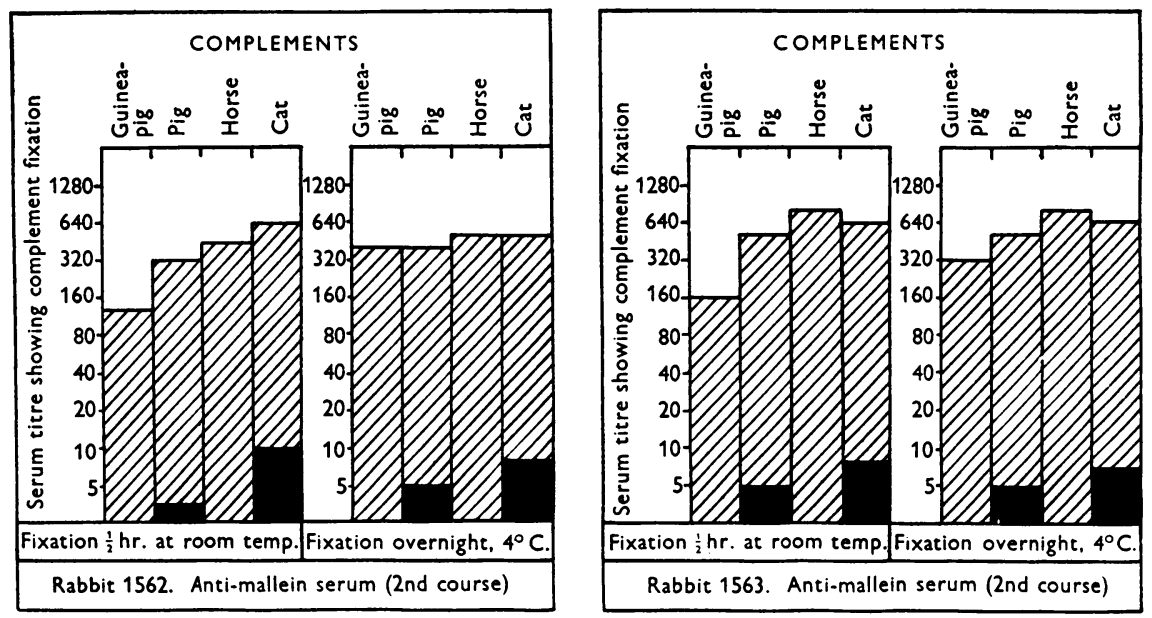

Fig. 6. The demonstrable titre of specific antibodies to mallein in two rabbit sera using four different complements.
Ferret sera. Horse complement, closely followed by that of the cat, is the most sensitive in detecting anti-mallein antibodies in this species. Pig and guinea-pig complements are both fixed to a lower titre which rises slightly with overnight fixation.

Rat sera. All four complements give practically the same titre after overnight fixation. Under the conditions of the room-temperature fixation test, horse complement and, to a lesser degree, cat com- plement give better results than pig and guinea-pig complements.

Hamster sera. The pattern of fixations given by hamster serum is very closely parallel with that given by ferret serum. Overnight fixation increases the titre shown by pig and guinea-pig complements, but even then they do not rise as high as the titres shown by horse complement or even cat complement.
The ferret, rat and hamster antisera tended to be anticomplementary to horse complement, but this may have been related to the fact that most of these sera were pooled samples.

Room-temperature fixation results compared with overnight fixation results

The tests using overnight fixation and room temperature fixation were set up at the same time, 
so that the serum dilutions should be exactly comparable. Overnight fixation makes most difference to the tests with guinea-pig complement. In these experiments the antibody titres increased. Cat, pig and perhaps guinea-pig sera, which failed to fix guineapig complement at room temperature, did give positive results when the fixation was carried out
This benefit by overnight fixation with guinea-pig and pig complements, which is not shown with horse and cat complements, may, however, be more apparent than real because, in the titration of com. plement, overnight exposure to the antigen scarcely affected the titres of guinea-pig or pig complements, whereas the end-point of horse and, to a lesser
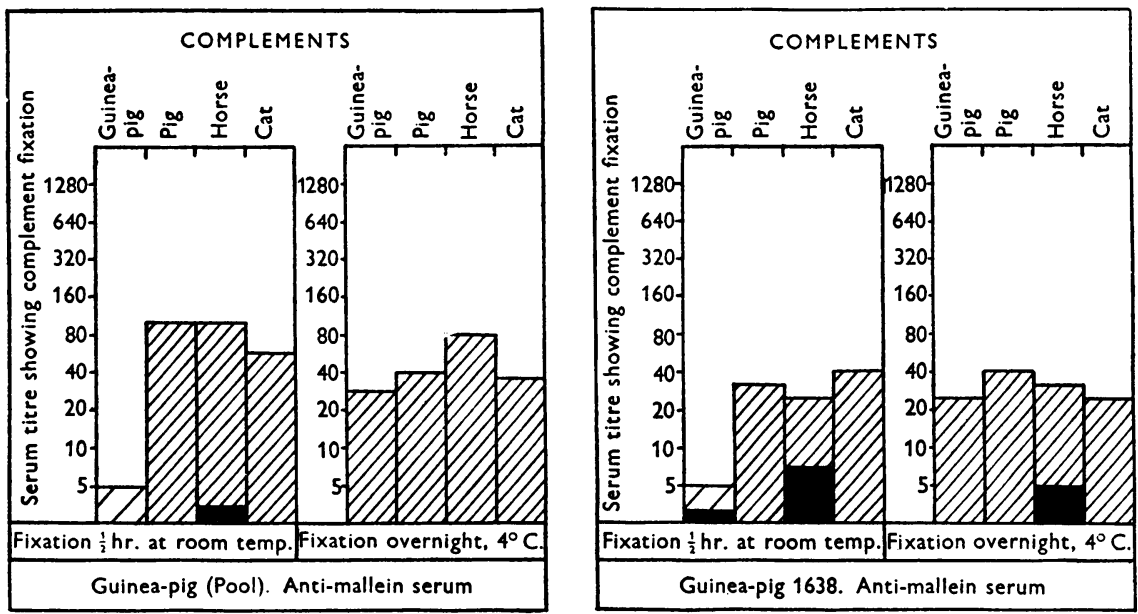

Fig. 7. The demonstrable titre of specific antibodies to mallein in two guinea-pig sera using four differenit complements.
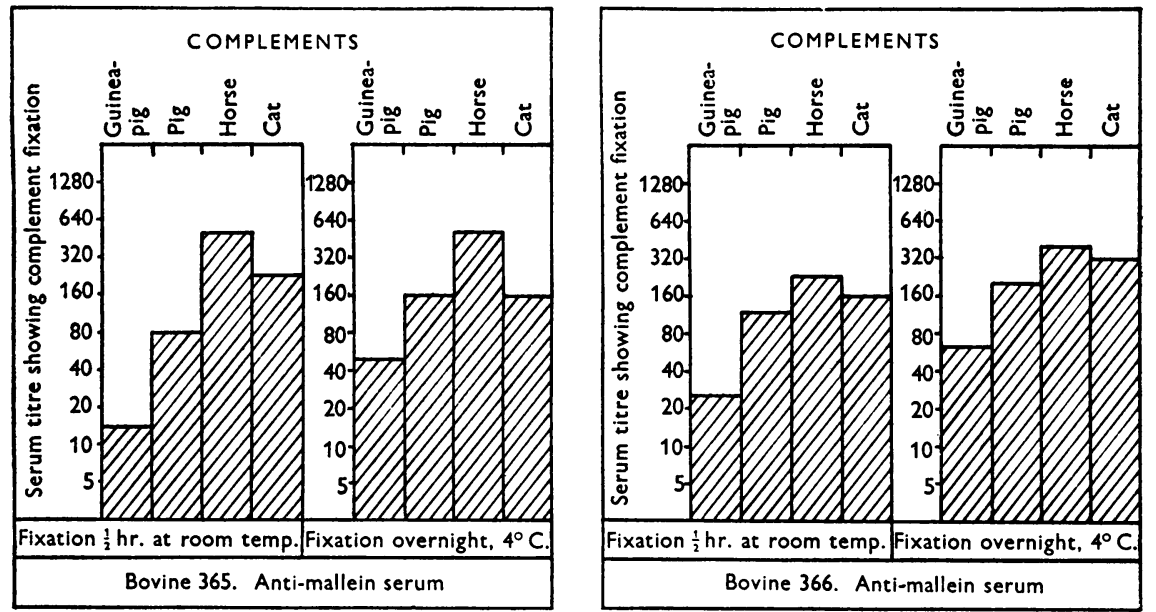

Fig. 8. The demonstrable titre of specific antibodies to mallein in two bovine sera using four different complements.

overnight at $4^{\circ} \mathrm{C}$. On the other hand, antibody titres, as demonstrated by horse and cat complements, were increased hardly at all by overnight fixation; in fact in some cases, notably in the goat, a fall of titre was recorded. With pig complement overnight fixation increased the serum titres slightly, and in some instances, for example dog L, fixation of pig complement was only obtained after overnight fixation. extent, of cat complement was always markedly reduced. The amount of serum used as guinea-pig or pig complement therefore remained essentially constant for both methods of fixation, whereas the amount used as horse or cat complement had to be increased to give 2 M.c.D. for the overnight method. It is possible that this may be the reason why the antibody titres in this system demonstrated with 
horse and cat complements do not show a rise when the overnight fixation method is used.

However, despite the advantage of overnight fixation for guinea-pig complement in the experiments here recorded, horss conglutinating complement remained the most sensitive complement, giving the highest titres of fixation in the sera examined. in the serum of each species in the presence of the homologous antigen. We have performed each test using both the method of fixing for half an hour at room temperature and of fixing overnight at $4^{\circ} \mathrm{C}$.

Two minimal complement doses of guinea-pig complement are fixed by less antibody when exposed overnight at $4^{\circ} \mathrm{C}$. than when exposed for half an
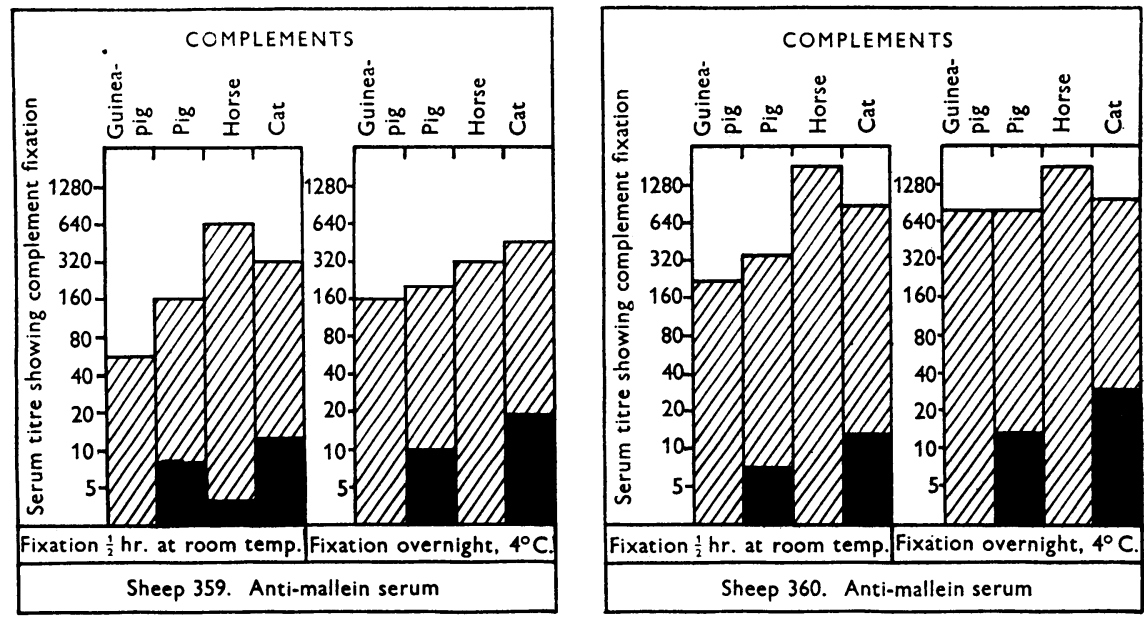

Fig. 9. The demonstrable titre of specific antibodies to mallein in two sheep sera using four different complements.
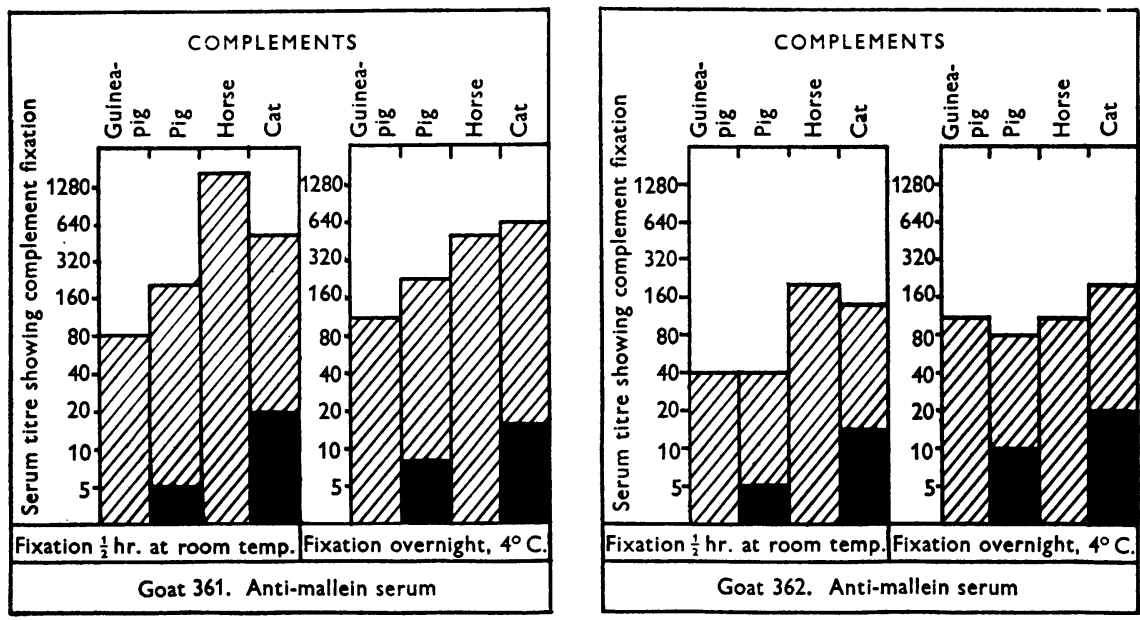

Fig. 10. The demonstrable titre of specific antibodies to mallein in two goat sera using four different complements.

\section{DISCUSSION}

We have now examined anti-mallein sera from thirteen different species of mammals, including man, and from one species of bird by both conglutinating complement-absorption and haemolytic comple. ment-fixation tests. We have ascertained, for this particular antigen-antibody system, which of the four complements, horse, cat, pig, or guinea-pig, is the most sensitive in detecting the specific antibodies hour at room temperature. The same is true, but is much less marked, in the case of pig complement. The sensitivity of horse and cat complements is not enhanced by overnight fixation. The reason for this difference may lie in the effect on the complement titration of prolonged exposure to the antigen. The titres of guinea-pig and pig complements were unchanged by overnight exposure to the antigen before adding the indicator system; the titres of horse and cat complements, on the other hand, were markedly 


\section{A. M. Blomfield, R. R. A. Coombs and N. H. Hole}

reduced, and thus more complement had to be used in the overnight fixation test. This additional amount of horse and cat complement may have masked any rise in the serum titres which might have been shown by these complements in overnight tests. On the other hand, the fact that horse complement is much more sensitive than is guinea-pig complement to absorption by an antigen-antibody haemolytic and conglutinating complements would be fairer if the techniques used were identical, but any advantage in this respect lies with the haemolytic complement, for comparatively more complement is used in the C.C.A.T. than in the H.C.F.T. Horse complement therefore is even more sensitive, compared with guinea-pig, than is shown in this paper. It would be possible to amend the technique
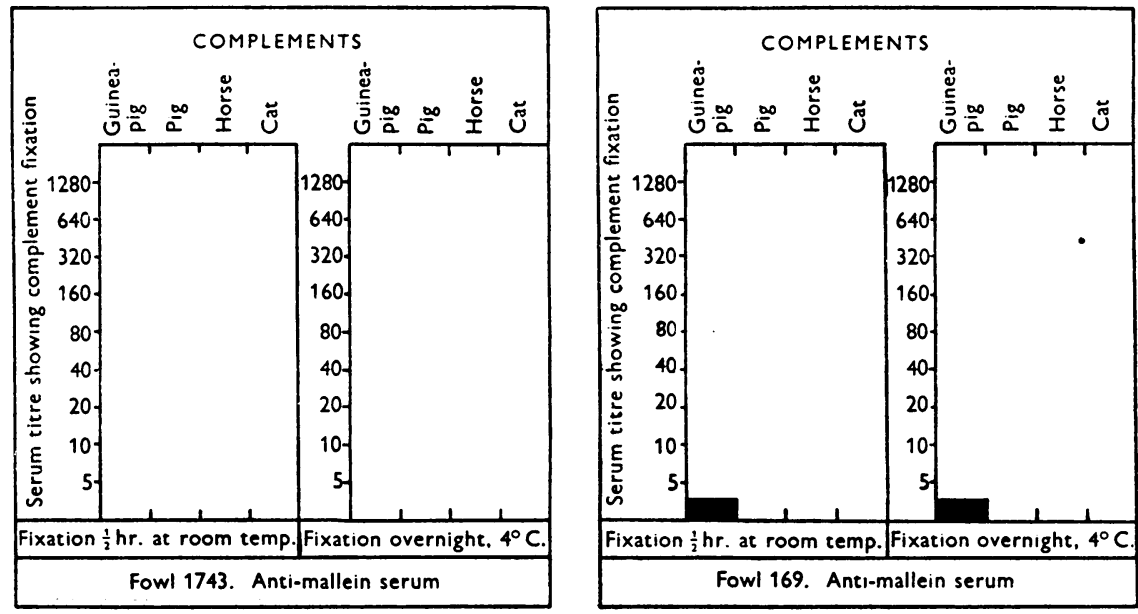

Fig. 11. The demonstrable titre of specific antibodies to mallein in two fowl sera using four different complements.
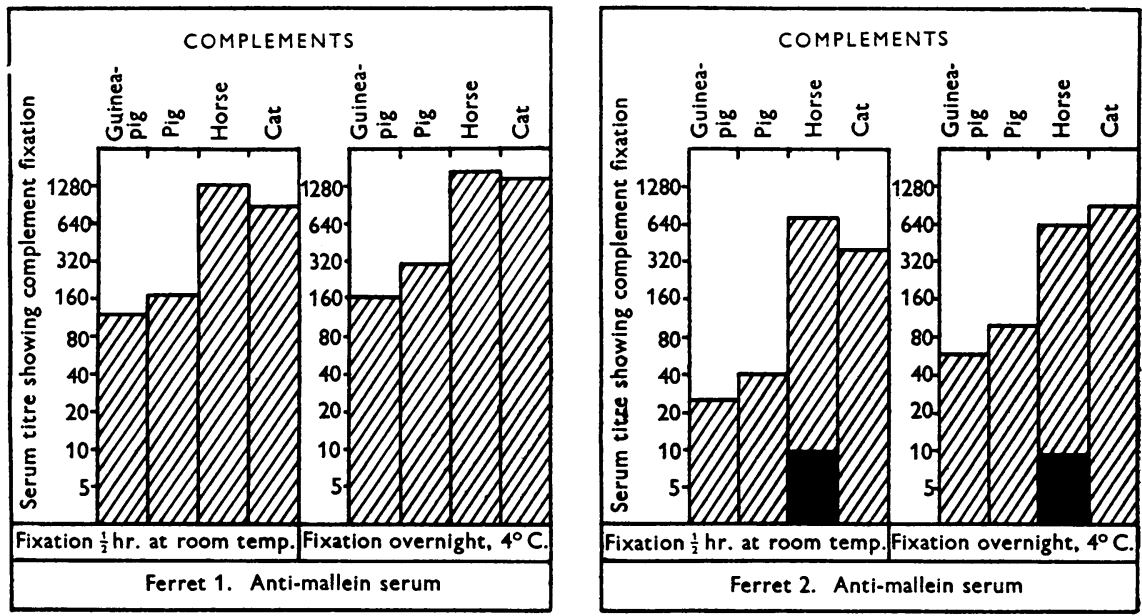

Fig. 12. The demonstrable titre of specific antibodies to mallein in two ferret sera using four different complements.

complex may suggest that maximal fixation of horse complement occurs in a much shorter time.

It should be borne in mind that in the technique we have adopted for this work the minimal complement dose for the H.C.F.T. is based on partial haemolysis (approximately 50\%), and not on complete haemolysis; whereas with the C.C.A.T. the endpoint of a complement titration is taken as complete conglutination. Comparison of results obtained with to obtain these more sensitive results, but while it is easy to read degrees of haemolysis, consistent estimation of degrees of partial conglutination is more difficult, and we prefer to leave the method of complement titration as it is.

We have some evidence that the overall picture of the complement-absorption properties of an antiserum, as depicted in any of these figures, may change, according to the stage of immunization of 
the animal ; it is agreed that the physical properties of serum antibodies change over the course of immunization (see Raffel, Pait \& Terry, 1940; Raffel \& Terry, $1940 a, b)$.

The results obtained with the bovine antisera are confirmed for another antigen-antibody system by the work of Wolfe \& Kornfeld (1948), who com. showed specific titres four to eight times higher than those obtained by the H.C.F.T. using the overnight fixation method, the latter in turn being four to eight times higher than the titres obtained by warm bath fixation.

The inability of the fowl antisera to fix any of the conglutinating or haemolytic complements is most
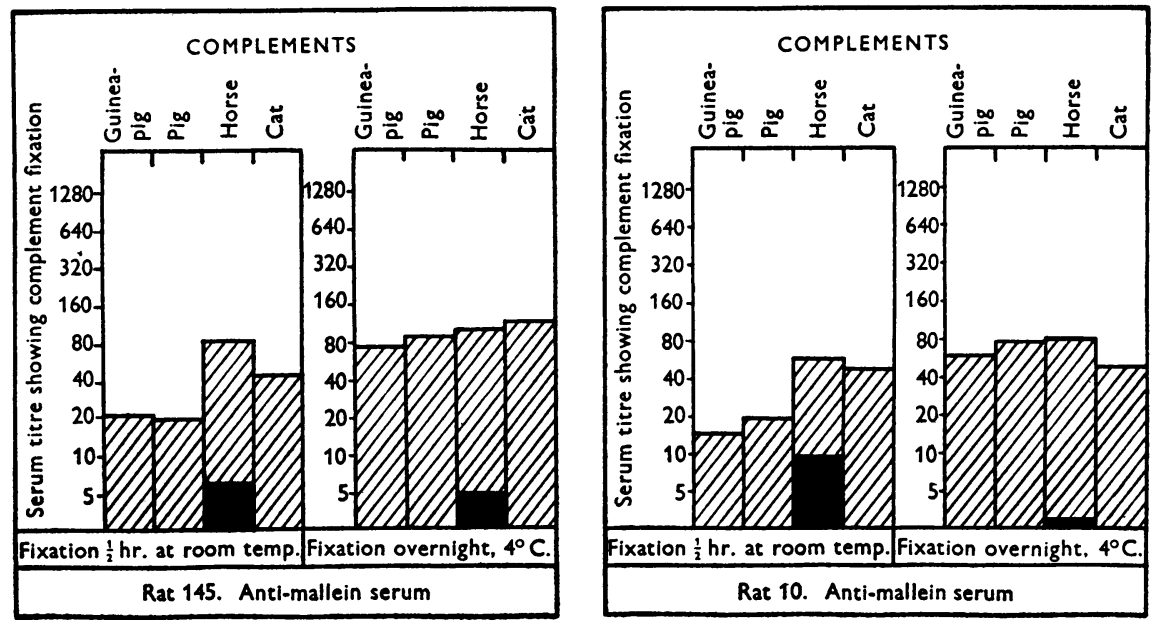

Fig. 13. The demonstrable titre of specific antibodies to mallein in two rat sera using four different complements.
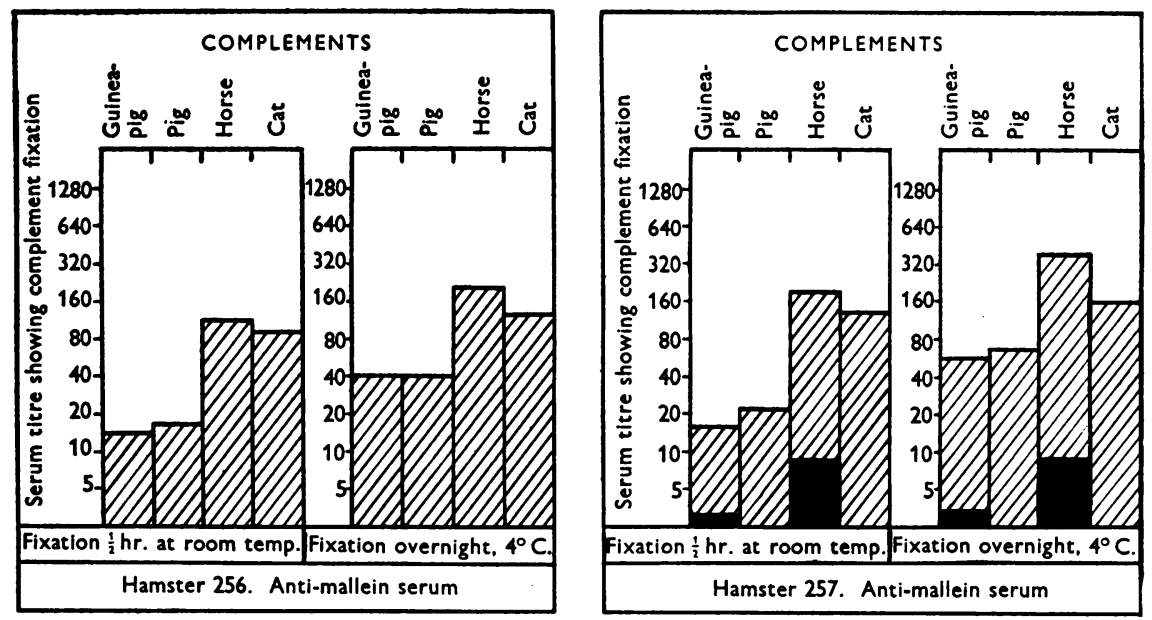

Pig. 14. The demonstrable titre of specific antibodies to mallein in two hamster sera using four different complements.

pared the C.C.A.T., using horse complement, with the usual H.C.F.T. for the examination of $Q$ fever immune bovine sera. In these experiments the fixation period for the C.C.A.T. was half an hour at room temperature, while periods of $1 \mathrm{hr}$. at $37^{\circ} \mathrm{C}$. and $24 \mathrm{hr}$. at $4^{\circ} \mathrm{C}$. were used in the H.C.F. tests. Despite this fixation advantage for the haemolytic test, they found the sera tested by the C.C.A.T. interesting, and confirms the findings of Rice $(1948 a, b)$. She found that serum antibodies to $S$. pullorum in chickens, ducks, geese and turkeys did not fix guinea-pig complement in the presence of the homologous antigen in the form of either a bacterial suspension or an extract. However, the antibodies could be demonstrated after their addition to the homologous antigen, because it was found 


\section{A. M. Bloomfield, R. R. A. Coombs and N. H. Hole}

that the fixation of complement by a rabbit antipullorum serum, added subsequently to the mixture, was specifically inhibited. This procedure she calls the Indirect Complement Fixation Test. Applying this I.C.F.T. it was found that our fowl anti-mallein sera were able to specifically inhibit the absorption of guinea-pig complement by a subsequently added rabbit anti-mallein serum, and that similar specific inhibition obtained when horse, cat, or pig conglutinating complements were used instead of guinea-pig haemolytic complement.

As the nature of the antigen, as well as that of the antibody, helps to determine the nature and properties of the immune aggregate it is not possible to accept these results as representative of all antigenantibody systems, but they do represent the results that may be expected with a particular type of antigen.

Disregarding for the moment the nature of the antigen it seems that, besides the intrinsic nature of the antibody molecule itself, certain properties of the serum as a whole modify the degree to which a particular antiserum gives demonstrable fixation of a complement. Experimental work on this aspect will be reported in a later paper.

To conclude on a more practical note, it may be said that in our early experiments applying the C.C.A.T. to different antigen-antibody systems satisfactory results have been obtained using virus antigens, and that $\mathrm{J}$. Bullen, in a personal communication, has informed us that he has had satisfactory results using fungus antigens in the form of both whole organism suspensions and extracts.

\section{SUMMARY}

1. Anti-mallein sera produced in thirteen species of mammals (including man) and one species of bird have been examined by the haemolytic complement fixation test using guinea-pig complement, and by the conglutinating complement absorption test using pig, horse and cat complements. Two methods of fixation have been used and compared, namely, fixation for half an hour at room temperature and fixation overnight at $4^{\circ} \mathrm{C}$.

2. The complement of the horse proved to be the most sensitive in nearly every case in demonstrating the specific antibodies in the different sera; in the few instances where it was not markedly the most sensitive it was for practical purposes the equal of any other complement used, independent of the method of fixation. This is clearly indicated in the text figures.

3. The effects of overnight fixation on the titres obtained with the different complements are discussed.

4. The sera of six fowls inoculated with mallein failed to show fixation of any of the four complements in the presence of the homologous antigen. The presence of immune bodies was demonstrated however by the Indirect Complement Fixation technique of Rice (1948b).

\section{REFERENCES}

Coombs, R. R. A. \& Hole, N. H. (1948). J. Hyg., Camb., 46, 296.

Dean, H. R. (1917). J. Path. Bact. 21, 193.

Hole, N. H. \& Coombs, R. R. A. (1947a). J. Hyg., Camb., 45, 480.

Hole, N. H. \& Coоmвs, R. R. A. (1947b). J. Hyg., Camb., 45, 490.

Hole, N. H. \& Coombs, R. R. A. (1947c). J. Hyg., Camb., 45, 497.
RAFFel, S., PaIt, C. F. \& Terry, M. C. (1940). $J$. Immunol. 39, 317.

RAFFel, S. \& TeRRY, M. C. (1940a). J. Immunol. 39, 337.

RAFFel, S. \& TERRY, M. C. (1940b). J. Immunol. 39,349.

RICE, C. E. (1948a). J. Immunol. 59, 365.

RICE, C. E. $(1948 b)$. J. Immunol. 60, 11.

Wolfe, D. M. \& Kornfeld, L. (1948). Proc. Soc. Exp, Biol., N.Y., 69, 251.

(MS. received for publication 27. IV. 49.-Ed.) 